\title{
Internal Medicine Residents' Perceived Responsibility for Patients at Hospital Discharge: A National Survey
}

Eric Young, $M D^{1,2}$, Chad Stickrath, $M D^{3}$, Monica C. McNulty, $M S^{1}$, Aaron J. Calderon, $M D^{4}$, Elizabeth Chapman, $M D^{5}$, Jed D. Gonzalo, MD, MSC ${ }^{6}$, Ethan F. Kuperman, MD, MS ${ }^{7,8}$, Max Lopez, MD ${ }^{9,10}$, Christopher J. Smith, MD ${ }^{11}$, Joseph R. Sweigart, MD ${ }^{12}$, Cecelia N. Theobald, MD, MPH', and Robert E. Burke, MD, MS ${ }^{1,2}$

${ }^{1}$ University of Colorado, Anschutz Medical Campus, Aurora, CO, USA; ${ }^{2}$ VA Eastern Colorado Healthcare System, Denver, CO, USA; ${ }^{3}$ University of Colorado, Colorado Springs Branch, Colorado Springs, CO, USA; ${ }^{4}$ Saint Joseph Hospital, Denver, CO, USA; ${ }^{5}$ University of Wisconsin School of Medicine and Public Health, Madison, WI, USA; ${ }^{\circ}$ Pennsylvania State University College of Medicine, Hershey, PA, USA; ${ }^{7}$ University of lowa Carver College of Medicine, lowa City, IA, USA; ${ }^{8}$ lowa City VA Medical Center, lowa City, IA, USA; ${ }^{9}$ University of Vermont College of Medicine, Burlington, VT, USA; ${ }^{10}$ University of Mississippi Medical Center, Jackson, MS, USA; ${ }^{11}$ University of Nebraska Medical Center, Omaha, NE, USA; ${ }^{2}$ University of Kentucky College of Medicine, Lexington, KY, USA; ${ }^{13}$ Vanderbilt University Medical Center, Nashville, TN, USA.

BACKGROUND: Medical residents are routinely entrusted with transitions of care, yet little is known about the duration or content of their perceived responsibility for patients they discharge from the hospital.

OBJECTIVE: To examine the duration and content of internal medicine residents' perceived responsibility for patients they discharge from the hospital. The secondary objective was to determine whether specific individual experiences and characteristics correlate with perceived responsibility.

DESIGN: Multi-site, cross-sectional 24-question survey delivered via email or paper-based form.

PARTICIPANTS: Internal medicine residents (post-graduate years 1-3) at nine university and community-based internal medicine training programs in the United States. MAIN MEASURES: Perceived responsibility for patients after discharge as measured by a previously developed single-item tool for duration of responsibility and novel domain-specific questions assessing attitudes towards specific transition of care behaviors.

KEY RESULTS: Of 817 residents surveyed, 469 responded (57.4\%). One quarter of residents $(26.1 \%)$ indicated that their responsibility for patients ended at discharge, while $19.3 \%$ reported perceived responsibility extending beyond 2 weeks. Perceived duration of responsibility did not correlate with level of training $(P=0.57)$, program type $(P=0.28)$, career path $(P=0.12)$, or presence of burnout $(P=0.59)$. The majority of residents indicated they were responsible for six of eight transitional care tasks (85.1-99.3\% strongly agree or agree). Approximately half of residents (57\%) indicated that it was their responsibility to directly contact patients' primary care providers at discharge. and $21.6 \%$ indicated that it was their responsibility to ensure that patients attended their follow-up appointments.

CONCLUSIONS: Internal medicine residents demonstrate variability in perceived duration of responsibility for recently discharged patients. Neither the duration

Electronic supplementary material The online version of this article (doi:10.1007/s11606-016-3855-3) contains supplementary material, which is available to authorized users.

Published online September 14, 2016 nor the content of residents' perceived responsibility was consistently associated with level of training, program type, career path, or burnout, suggesting there may be unmeasured factors such as professional role modeling that shape these perceptions.

KEY WORDS: transitions of care; graduate medical education; internal medicine; readmissions.

J Gen Intern Med 31(12): 1490-5

DOI: $10.1007 / \mathrm{s} 11606-016-3855-3$

(C) Society of General Internal Medicine 2016

\section{BACKGROUND}

In recognition of common and costly readmissions, the Center for Medicare \& Medicaid Services (CMS) recently enacted penalties for 30-day readmissions. ${ }^{1,2}$ Despite financial incentives and growing attention from the medical community, significant inter-provider variability exists with regard to perceived responsibility in the post-discharge period. ${ }^{3,4}$ A recent study of practicing hospitalists found that $29 \%$ believed their responsibility for patients ended at the time of discharge, while $26 \%$ believed their responsibility extended beyond 2 weeks. ${ }^{5}$ Primary care providers express similar variability regarding the timing and content of their responsibility for patients after discharge. ${ }^{4,6}$ As a result, a responsibility gap often exists for recently discharged patients in which the delineation between inpatient and outpatient provider responsibilities is undefined.

Perceived responsibility is essential for ensuring that discharging providers adopt the transition of care practices outlined in consensus guidelines. ${ }^{7}$ The theory of planned behavior argues that an individual's decision to adopt a specific behavior is dependent upon three factors: social pressure, perceived self-efficacy, and his or her fundamental attitude towards that behavior. ${ }^{8}$ It therefore stands to reason that if a clinician does not possess an attitude of responsibility for patients after they leave the hospital, he or she will be unlikely to adopt the often time-consuming practices required to optimize post-discharge care. 
From the beginning of residency, internal medicine house staff play pivotal roles transitioning patients across the care continuum. We know that attitudes and practice patterns developed early in training persist for years into clinical practice. ${ }^{9,10}$ However, the literature currently offers limited insight into medical residents' attitudes towards transitions of care. ${ }^{3,11}$. We sought to examine the duration and content internal medicine residents' perceived post-discharge responsibility and determine whether specific individual characteristics and experiences correlate with perceived responsibility.

\section{METHODS}

\section{Study Design}

We conducted a cross-sectional, 24-question survey (see Online Appendix A) of internal medicine residents at nine US university and community-based residency programs. Program size ranged from 38 to 170 resident physicians (mean 91). The study was approved by the Colorado Multiple Institutional Review Board along with the institutional review boards at each participating site.

\section{Residency Programs and Participants}

We used purposive sampling and existing professional relationships to identify sites that differed in program size and geographic location.

\section{Survey Instrument}

There was no existing gold standard instrument for measuring perceived responsibility for patients transitioning from inpatient to outpatient environments. We developed a new instrument, approaching this construct through two methods. First, we utilized a single question derived from prior work in this area to assess the perceived duration of post-discharge responsibility ("How many days are inpatient providers responsible for their patients after they are discharged?"). ${ }^{5}$ To further explore the content of responsibility, we developed specific questions to assess residents' perceived responsibility within four key domains in transitions of care: (1) medication reconciliation, ${ }^{12}$ (2) lab follow-up, ${ }^{13,14}$ (3) postdischarge follow-up appointments, ${ }^{15,16}$ and (4) communication with outpatient providers ${ }^{17}$. Within each of these domains, one question was developed to assess residents' perceived responsibility for discharge practices currently considered the standard of care based on consensus policy statements from multiple large professional societies ${ }^{7,18}$ (e.g., "As an inpatient provider, I am responsible for ensuring that labs pending at the time discharge are accurately documented in my discharge summary"). The second question in each domain was designed to assess their perceived responsibility for behaviors considered to be above and beyond the standard of care based on expert opinion and consensus guidelines (e.g., "As an inpatient provider, I am responsible for ensuring that labs pending at the time of discharge receive appropriate follow-up when the results become available"). Responses to these eight questions were ranked on a fourpoint Likert scale (strongly agree $=4$, strongly disagree $=1$ ) . This tiered questioning within each domain was employed to create stratification amongst respondents. All questions were refined in two sequential heterogeneous focus groups of 6-8 attending and resident physicians in which a "think-aloud" cognitive interviewing approach was utilized to ensure consistency in question interpretation.

There is a paucity of data about individual characteristics that correlate with perceived attitudes towards transitions of care. Therefore, we used expert opinion and relevant qualitative data $^{3,11}$ to iteratively decide upon nine factors that we believed might correlate with perceived post-discharge responsibility. Post-graduate year, participation in a community-based versus university-based program, and anticipated career path were assessed based on demographic questions. Burnout was assessed using a validated two-item tool assessing emotional exhaustion and depersonalization. ${ }^{19}$ Prior experiences with barriers to ensuring successful transitions of care were assessed using an internally generated question ("In the hospital or healthcare system where you spend the majority of your inpatient clinical time, how often do you experience difficulty arranging timely post-discharge follow-up with primary care physicians?"). Perceived self-efficacy in ensuring safe transitions of care and perceived importance of readmissions were assessed using internally generated questions ranked on the same four-point Likert scale previously described ("As an inpatient provider, I believe I can prevent readmissions" and "Hospital readmissions within 30 days are an important problem for the healthcare system"). Respondents' understanding of the burden of readmissions was evaluated using a single multiple choice question based on existing literature ("What percentage of Medicare patients are readmitted within 30 days of hospital discharge nationally?"). ${ }^{20}$ Finally, residents were asked to rank the impact of six potential barriers to ensuring successful transitions of care derived from expert opinion and prior qualitative studies. ${ }^{3,4,11}$

\section{Data Collection}

The survey was delivered through local educational leaders, either via email using SurveyMonkey ${ }^{\circledR}$ (SurveyMonkey Inc., Palo Alto, CA) or in paper-based form, between September 2014 and February 2015. The initial survey invitation was followed by three reminder emails at all sites but one, where only two were sent based on local IRB restrictions.

\section{Analysis and Outcomes}

Data were analyzed using SAS 9.3 software (SAS Institute, Inc., Cary, NC). Survey responses were analyzed using descriptive statistics. Between-group comparisons were made using Chi-square tests, and correlations between variables were analyzed using the Kendall rank correlation coefficient. 


\section{RESULTS}

Of 817 internal medicine residents among the nine programs, 469 responded to the survey $(57.4 \%)$. Site response rates ranged from $45 \%$ to $76 \%$, with the majority of responses $(95.3 \%)$ coming from university-based programs (Table 1). Respondents were balanced across post-graduate years (PGY), and the majority (60.5\%) indicated an intention to pursue a subspecialty career.

Of the residents who completed the survey, $40.9 \%$ were classified as experiencing burnout based on the presence of emotional exhaustion and/or depersonalization at least once a week. The prevalence of burnout did not differ between PGY groups $(\mathrm{PGY}-1=44.2 \%$, PGY-2 $=36.4 \%$, and PGY-3 $=$ $41.0 \%, P=0.46)$. The majority of respondents $(96.1 \%)$ agreed that readmissions are an important problem for our health care system, though one quarter $(25.9 \%)$ could not accurately identify the average rate of 30-day readmissions for Medicare patients. The majority of respondents (87.4\%) agreed that they could prevent readmissions, despite $77.2 \%$ reporting difficulty arranging post-discharge follow-up at least once per week. Residents ranked lack of time, patient factors,

Table 1 Participant Characteristics

\begin{tabular}{ll}
\hline \hline Characteristic & $\begin{array}{l}\text { No./Total no.* } \\
(\mathbf{\%})\end{array}$ \\
\hline Post-graduate year (PGY) & \\
PGY-1 & $163 / 420(38.8)$ \\
PGY-2 & $126 / 420(30.0)$ \\
PGY-3 & $131 / 420(31.2)$ \\
Missing responses & 49 \\
Anticipated career path & $86 / 420(20.5)$ \\
Primary care & $80 / 420(19.0)$ \\
Hospital medicine & $254 / 420(60.5)$ \\
Subspecialty & 49 \\
Missing responses & $22 / 469(4.7)$ \\
Community programs & $447 / 469(95.3)$ \\
University-based programs & $126 / 469(26.9)$ \\
Program region & $126 / 469(26.9)$ \\
West & $123 / 469(26.2)$ \\
Midwest & $94 / 469(20.0)$ \\
Southeast & $157 / 384(40.9)$ \\
Northeast & 85 \\
Burned out ${ }^{\dagger}$ & $339 / 439(77.2)$ \\
Missing responses & \\
Experience difficulty arranging post-discharge fol- & \\
low-up once a week or more & 30 \\
Missing responses & $423 / 440(96.1)$ \\
Agree that readmissions are an important problem for & \\
our healthcare system & 29 \\
Missing responses & $410 / 469(87.4)$ \\
Agree that "as an inpatient provider, I can prevent & \\
readmissions" & $321 / 439(73.1)$ \\
Correctly answered the multiple choice question, \\
"What percentage of Medicare patients are \\
readmitted within 30 days of hospital discharge \\
nationally?" \\
Missing responses & \\
\hline
\end{tabular}

* Missing responses were excluded from the denominator of each calculation of percentage of total responses. The number of missing responses is identified under each characteristic for which responses were missing.

${ }^{\dagger}$ Burnout was defined as the presence of emotional exhaustion and/or depersonalization at least once per week. At one of the nine sites, with 56 respondents, the two-item burnout tool was not delivered. These missing responses were excluded from the denominator, along with the other 29 missing responses from other sites. and shortage of ancillary staff as the most challenging barriers to ensuring safe transitions of care (Table 2).

With regard to perceived duration of post-discharge responsibility, $26.1 \%$ of respondents indicated that inpatient providers' responsibility for patients ends at the time of discharge, while $43.3 \%$ indicated that the responsibility extended beyond discharge but for 1 week or less (Fig. 1). A smaller percentage $(19.3 \%)$ reported a perception of responsibility extending 15-30 days after discharge. Perceived duration of responsibility did not differ between post-graduate years $(P=0.57)$ or between participants from university and community-based programs (correlation coefficient $0.05, P=$ 0.28 ). Perceived duration of responsibility also did not differ between residents with different career paths (correlation coefficient $-0.06, P=0.12$ ). The presence of burnout, defined as high emotional exhaustion and/or high depersonalization, was not correlated with perceived duration of post-discharge responsibility (correlation coefficient $-0.02, P=0.59$ ). The presence of both high emotional exhaustion and high depersonalization showed a trend towards correlation with shorter duration of post-discharge responsibility; however, it did not meet statistical significance (correlation coefficient -0.08 , $P=0.06$ ). Perceived importance of readmissions was correlated with longer durations of post-discharge responsibility (correlation coefficient $0.17, P<0.001$ ). Perceptions of high self-efficacy in preventing readmissions showed a trend towards correlating with longer post-discharge responsibility, but did not reach statistical significance (correlation coefficient $0.07, P=0.07$ ). Knowledge regarding national hospital readmission rates did not correlate with perceived duration of post-discharge responsibility (correlation coefficient -0.01 , $P=0.82$ ). There was heterogeneity in attitudes across sites, with the percentage of residents at each site indicating that

Table 2 Perceived Barriers to Ensuring Safe Transitions of Care

\begin{tabular}{ll}
\hline \hline Barriers & $\begin{array}{l}\text { No./Total no.* } \\
(\%)\end{array}$ \\
\hline $\begin{array}{l}\text { Lack of time to adequately prepare patients for } \\
\text { discharge }\end{array}$ & $136 / 395(34.4)$ \\
$\begin{array}{l}\text { Patient factors, such as social situation or health } \\
\text { literacy }\end{array}$ & $112 / 395(28.4)$ \\
$\begin{array}{l}\text { Shortage of ancillary staff to help prepare patients } \\
\text { for discharge }\end{array}$ & $77 / 395(19.5)$
\end{tabular}

Difficulty arranging adequate follow-up after hospital discharge

Difficulty communicating with primary care physicians

My uncertainty about how to provide a safe discharge

Missing responses ${ }^{\dagger}$

$39 / 395(9.9)$

$23 / 395(5.8)$

$8 / 395(2.0)$

74

*Indicates the number of residents who ranked each potential barrier as having the greatest impact on their ability to ensure safe transitions of care, divided by the total number of responses to the question. Missing responses were excluded from the denominator of each calculation of percentage of total responses, and the number of missing responses is indicated at the bottom of the table.

${ }^{\prime}$ At one of the nine sites, with 56 respondents, this question was not delivered. These missing responses were excluded from the denominators, along with the other 18 missing responses from other sites. 


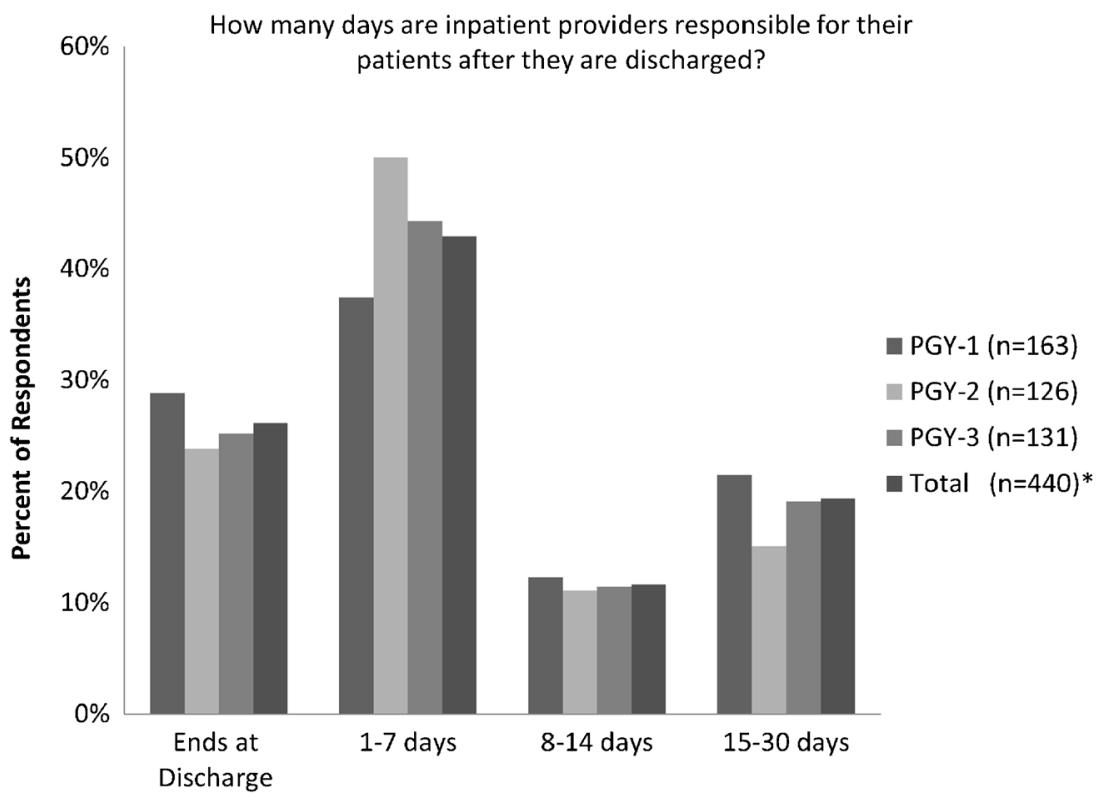

Fig. 1 Residents' perceived duration of responsibility for patients after discharge. *Missing responses were excluded from the denominator of each calculation of percentage of total response. Respondents who answered the duration of responsibility question but did not answer the level of training question were included in the "total" category, which explains why the sum of total responses is higher than the sum of all the PGY group responses.

responsibility ends at discharge ranging from $18 \%$ to $37 \%$ (see Online Appendix B).

With regard to the content of transitional care responsibilities, resident's perceived responsibility was high in all four domain-specific standard of care behaviors (Table 3, 88.6$99.3 \%$ strongly agree or agree). For behaviors identified as surpassing the standard of care, residents' perceived responsibility showed greater heterogeneity (21.6-85.2\% strongly agree or agree). Approximately half of the residents $(57.0 \%)$ strongly agreed or agreed that it was their responsibility to contact patients' primary care providers directly at discharge, and $21.6 \%$ indicated it was their responsibility to ensure patients attended their follow-up appointments. Among the eight domain-specific questions, there was no difference in perceived responsibility between post-graduate years. Participation in a community-based program was associated with one difference within the domain-specific questions: $47.6 \%$ of residents in community programs reported responsibility for ensuring that labs received follow-up after discharge, in comparison to $87.1 \%$ in university-based programs $(P<0.001)$. Career path was associated with a statistically significant difference in one content question, namely perceived responsibility for ensuring an accurate medication list at discharge ( subspecialty $=100 \%$, hospitalist $=97.5 \%$, and primary care $=97.7 \%$ strongly agreed or agreed, $P=0.02$ ). Only one domain-specific question showed a statistically significant association with burnout: residents experiencing burnout were less likely to report feeling responsible for ensuring that follow-up appointments were scheduled prior to discharge than those without burnout $(84.1 \%$ and $91.6 \%$ strongly agreed or agreed, respectively, $P=0.02$ ).

\section{DISCUSSION}

In this national survey of internal medicine residents, perceived duration of responsibility for patients after hospital discharge varied considerably. Over one quarter of residents indicated that their responsibility ended at discharge, while nearly the same amount indicated that their responsibility extended beyond 2 weeks. Perceived duration of responsibility did not appear to be impacted by level of training, program type, career path, or burnout; however, residents who believed readmissions were an important problem or had high perceived self-efficacy in preventing readmissions reported longer durations of responsibility. This variability in perceived duration of responsibility has important implications for policymakers and educators seeking to build a physician workforce with the attitudes and skills necessary to facilitate successful transitions of care.

In particular, the variability identified in this study highlights the lack of standardized expectations for physician responsibility in the post-discharge period. ${ }^{4}$ While 30 -day readmission penalties imply that inpatient providers have some responsibility extending beyond the hospital, consensus guidelines are not proscriptive in defining its duration or content. ${ }^{2,7}$ As a potential by-product, attending hospitalists report variable perceptions of post-discharge responsibility that are strikingly similar to the attitudes reported by residents in this study. ${ }^{4,5,21}$ This leads us to hypothesize that role modeling, a critical determinant of professional development, ${ }^{22}$ may be the most influential determinant of residents' perceptions of post-discharge responsibility. Further work is needed to verify this hypothesis and to create acceptable standards of post-discharge responsibility that facilitate more consistent role modeling. 
Table 3 Residents' Perceived Responsibility for Specific Transition of Care Activities

\begin{tabular}{|c|c|c|c|c|}
\hline \multirow[t]{3}{*}{ Domain-specific questions } & \multirow{3}{*}{$\begin{array}{l}\text { All residents } \\
\begin{array}{l}\text { Strongly agree } \\
\text { or agree }\end{array} \\
\begin{array}{l}\text { No./Total no.* } \\
(\%)\end{array}\end{array}$} & \multirow{3}{*}{$\begin{array}{l}\text { Burned out } \\
\text { Strongly agree } \\
\text { or Agree } \\
\begin{array}{l}\text { No./Total no. } \\
(\%)\end{array}\end{array}$} & \multirow{3}{*}{$\begin{array}{l}\text { Not burned out } \\
\text { Strongly agree } \\
\text { or agree } \\
\text { No./Total no. } \\
(\%)\end{array}$} & \multirow{3}{*}{$\begin{array}{l}P \\
\text { value }\end{array}$} \\
\hline & & & & \\
\hline & & & & \\
\hline \multicolumn{5}{|l|}{ Medication reconciliation } \\
\hline \multicolumn{5}{|l|}{ As an inpatient provider I am responsible for... } \\
\hline ensuring that my patients leave the hospital with an accurate medication list. & $464 / 469(98.9)$ & $157 / 157(100)$ & $222 / 227(97.8)$ & 0.06 \\
\hline $\begin{array}{l}\text { ensuring that prior to discharge my patients receive in-person education } \\
\text { about how and why they take each medication on their list. }\end{array}$ & $399 / 469(85.1)$ & $132 / 157(84.1)$ & $198 / 227(87.2)$ & 0.38 \\
\hline \multicolumn{5}{|l|}{ Lab follow-up } \\
\hline $\begin{array}{l}\text { As an inpatient provider I am responsible for... } \\
\text { ensuring that labs pending at the time discharge are accurately documented in }\end{array}$ & $423 / 440(96.1)$ & $151 / 157(96.2)$ & $222 / 227(97.8)$ & 0.35 \\
\hline $\begin{array}{l}\text { my discharge summary. } \\
\text { ensuring that labs pending at the time of discharge receive appropriate } \\
\text { follow-up when the results become available. }\end{array}$ & $375 / 440(85.2)$ & $136 / 157(86.6)$ & $193 / 227(85.0)$ & 0.66 \\
\hline Missing responses & 29 & & & \\
\hline \multicolumn{5}{|l|}{ Post-discharge follow-up } \\
\hline $\begin{array}{l}\text { As an inpatient provider I am responsible for... } \\
\text { ensuring my patients have a follow-up appointment scheduled prior to } \\
\text { discharge. }\end{array}$ & $389 / 439(88.6)$ & $132 / 157(84.1)$ & 208/227 (91.6) & 0.02 \\
\hline $\begin{array}{l}\text { ensuring my patients attend a follow-up appointment after discharge. } \\
\text { Missing responses }\end{array}$ & $\begin{array}{l}95 / 439(21.6) \\
30\end{array}$ & $32 / 157(20.4)$ & $52 / 227(22.9)$ & 0.56 \\
\hline \multicolumn{5}{|l|}{ Communication with follow-up providers } \\
\hline \multicolumn{5}{|l|}{ As an inpatient provider I am responsible for... } \\
\hline $\begin{array}{l}\text { completing an accurate discharge summary within } 48 \text { hours of my } \\
\text { patient's discharge. }\end{array}$ & $436 / 439(99.3)$ & $155 / 157(98.7)$ & 226/227(99.6) & 0.36 \\
\hline $\begin{array}{l}\text { calling or emailing my patients' primary care providers at the time of } \\
\text { discharge. }\end{array}$ & $250 / 439(57.0)$ & $92 / 157(58.6)$ & $138 / 227(60.8)$ & 0.67 \\
\hline Missing responses & 30 & & & \\
\hline
\end{tabular}

Interestingly, residents in our study demonstrated less variability in their perceived responsibility for specific transitional care tasks. Perceived responsibility was consistently high for six of the eight domain-specific transitional care behaviors assessed. Residents simultaneously reported frequent difficulty arranging post-discharge follow-up, ranking lack of time, patient factors, and lack of ancillary support as major barriers to ensuring safe transitions of care. Notably, burnout did not consistently correlate with perceived responsibility for transitional care activities, suggesting that residents may not abdicate their sense of responsibility as they develop symptoms of burnout. This leads us to hypothesize that the tension created by coupling high personal task responsibility and difficult-toovercome barriers may actually fuel burnout amongst residents. This conclusion is supported by prior research indicating that residents play a central role in the complex web of inpatient discharge planning, ${ }^{23}$ despite feeling ill-prepared and perpetually distracted by other tasks. ${ }^{3,11}$ This imbalance between the demands of work and the time and skills available to meet those demands is the classic foundation for burnout. ${ }^{24}$ Further research is needed to validate this hypothesis and to explore avenues for allowing residents to grow into their transitional care roles without imposing undue psychological burden.

Among the domain-specific questions, there was one notable outlier for which residents did not uniformly report high perceived responsibility. Communication between inpatient and outpatient providers is a fundamental component of safe transitions of care, ${ }^{25,26}$ yet only half of the residents in this national study indicated that they were responsible for directly contacting primary care providers at discharge. Perceived responsibility for direct communication did not vary based on level of training, program type, career path, or presence of burnout. The heterogeneity in responses to this item may also be attributable to role modeling. Prior national studies indicate that direct communication between inpatient and outpatient providers occurs in only $23 \%$ of hospital discharges. ${ }^{27}$ Hospitalists report frequent challenges in communicating directly with primary care providers, and therefore may utilize discretion in choosing which issues need to be communicated using a bidirectional modality (i.e., phone call or email). ${ }^{4}$ Thus, residents may be enculturated to believe that discharge summaries are a sufficient means of communication and that only select cases warrant direct communication. This is an important finding for attending physicians who supervise residents. It indicates that supervising physicians must be diligent in setting personal expectations regarding postdischarge communication and should proactively counsel residents regarding appropriate and inappropriate scenarios in which to rely on discharge summaries alone for coordination of care. 
Strengths of the study include its large sample size and the diversity of participating training programs. However, there are several important limitations. First, the question used for assessing duration of responsibility has strong face validity and has been used in prior studies, but has not undergone extensive testing of its psychometric properties. For other domains without existing tools in the literature, questions were developed internally without psychometric testing. As a crosssectional survey with a response rate of $57 \%$, the study is at risk of participation bias, though the response rate was similar to those of other surveys of medical residents. ${ }^{28}$ Furthermore, the responses to the primary outcome question were similar between the sites with the highest and lowest response rates (see Online Appendix B), which suggests that the effect of participation bias on the primary outcome was small. Finally, only internal medicine residents were surveyed; therefore, the results may not be indicative of the attitudes of residents in other specialties that also play a crucial role in care transitions.

\section{CONCLUSION}

In this national survey, internal medicine residents demonstrated notable variability in perceived duration of responsibility for recently discharged patients. Neither the duration nor the content of residents' perceived responsibility was consistently associated with level of training, program type, career path, or burnout, suggesting that there may be unmeasured factors such as professional role modeling that shape these perceptions.

Acknowledgments: This manuscript was presented at the Society of General Internal Medicine annual conference in Toronto in April 2015.

Corresponding Author: Eric Young, MD; University of Colorado, Anschutz Medical Campus, Aurora, CO, USA (e-mail: eric.young@ucdenver.edu).

\section{Compliance with ethical standards:}

Conflicts of Interest: The authors declare that they do not have a conflict of interest.

\section{REFERENCES}

1. Jencks SF, Williams MV, Coleman EA. Rehospitalizations among patients in the Medicare fee-for-service program. N Engl J Med. 2009;360(14):141828.

2. Joynt KE, Jha AK. A path forward on Medicare readmissions. N Engl J Med. 2013;368(13):1175-7.

3. Davis M, Devoe M, Kansagara D, Nicolaidis C, Englander H. "Did I do as best as the system would let me?" Healthcare professional views on hospital to home care transitions. J Gen Intern Med. 2012;27(12):1649-56.

4. Jones CD, Vu MB, O'Donnell CM, et al. A failure to communicate: A qualitative exploration of care coordination between hospitalists and primary care providers around patient hospitalizations. J Gen Intern Med. 2015;30(4):417-24.

5. Burke RE, Ryan P. Postdischarge clinics: Hospitalist attitudes and experiences. J Hosp Med. 2013;8(10):578-81.
6. Arora VM, Prochaska ML, Farnan JM, et al. Problems after discharge and understanding of communication with their PCPs among hospitalized seniors: A mixed methods study. J Hosp Med. 2010;5(7):385-91.

7. Snow V, Beck D, Budnitz T, et al. Transitions of care consensus policy statement: American College of Physicians, Society of General Internal Medicine, Society of Hospital Medicine, American Geriatrics Society, American College of Emergency Physicians, and Society for Academic Emergency Medicine. J Hosp Med. 2009;4(6):364-70.

8. Ajzen I. The theory of planned behavior. Organ Behav Hum Decis Process. 1991;50(2):179-211.

9. Chen C, Petterson S, Phillips R, Bazemore A, Mullan F. Spending patterns in region of residency training and subsequent expenditures for care provided by practicing physicians for medicare beneficiaries. JAMA. 2014;312(22):2385-93.

10. Papadakis MA, Teherani A, Banach MA, et al. Disciplinary action by medical boards and prior behavior in medical school. N Engl J Med. 2005;353(25):2673-82.

11. Greysen SR, Schiliro D, Horwitz LI, Curry L, Bradley EH. "Out of sight, out of mind": Housestaff perceptions of quality-limiting factors in discharge care at teaching hospitals. J Hosp Med. 2012;7(5):376-81.

12. Forster AJ, Murff HJ, Peterson JF, Gandhi TK, Bates DW. The incidence and severity of adverse events affecting patients after discharge from the Hospital. Ann Intern Med. 2003;138(3): 161-7.

13. Roy CL, Poon EG, Karson AS, et al. Patient safety concerns arising from test results that return after hospital discharge. Ann Intern Med. 2005; 143(2): 121-8.

14. Dalal AK, Roy CL, Poon EG, et al. Impact of an automated email notification system for results of tests pending at discharge: A clusterrandomized controlled trial. J Am Med Inform Assoc. 2014;21(3):473-80.

15. Misky GJ, Wald HL, Coleman EA. Post-hospitalization transitions: Examining the effects of timing of primary care provider follow-up. J Hosp Med. 2010;5(7):392-7.

16. Hernandez AF, Greiner MA, Fonarow GC, et al. Relationship between early physician follow-up and 30-day readmission among Medicare beneficiaries hospitalized for heart failure. JAMA. 2010;303(17):1716-22.

17. Kripalani S, LeFevre F, Phillips CO, Williams MV, Basaviah P, et al. Deficits in communication and information transfer between hospitalbased and primary care physicians: Implications for patient safety and continuity of care. JAMA. 2007;297(8):831-41.

18. Greenwald JL, Halasyamani L, Greene J, et al. Making inpatient medication reconciliation patient centered, clinically relevant and implementable: A consensus statement on key principles and necessary first steps. J Hosp Med. 2010;5(8):477-85.

19. West CP, Dyrbye LN, Sloan JA, Shanafelt TD. Single item measures of emotional exhaustion and depersonalization are useful for assessing burnout in medical professionals. J Gen Intern Med. 2009;24(12):1318-21.

20. Dharmarajan K, Hsieh AF, Lin Z, et al. Diagnoses and timing of 30-day readmissions after hospitalization for heart failure, acute myocardial infarction, or pneumonia. JAMA. 2013;309(4):355-63.

21. Beresford L. Hospitalists' responsibility, role in readmission prevention. Hospitalist. 2015;19(4): 1 .

22. Hafferty FW. Beyond curriculum reform: confronting medicine's hidden curriculum. Acad Med. 1998;73(4):403-7.

23. Pinelli VA, Papp KK, Gonzalo JD. Interprofessional communication patterns during patient discharges: A social network analysis. J Gen Intern Med. 2015;30(9): 1299-306.

24. Maslach C, Schaufeli WB, Leiter MP. Job burnout. Annu Rev Psychol. 2001;52:397-422

25. Kripalani S, Jackson AT, Schnipper JL, Coleman EA. Promoting effective transitions of care at hospital discharge: A review of key issues for hospitalists. J Hosp Med. 2007;2(5):314-23.

26. Auerbach AD, Kripalani S, Vasilevskis EE, et al. Preventability and causes of readmissions in a national cohort of general medicine patients. JAMA Intern Med. 2016;176(4):484-93.

27. Bell CM, Schnipper JL, Auerbach AD, et al. Association of communication between hospital-based physicians and primary care providers with patient outcomes. J Gen Intern Med. 2009;24(3):381-6.

28. Campbell J, Prochazka AV, Yamashita T, Gopal R. Predictors of persistent burnout in internal medicine residents: A prospective cohort study. Acad Med. 2010;85(10):1630-4. 